\title{
VDR Gene Polymorphisms and Risk of Hepatocellular Carcinoma
}

\author{
Ahmed Abudeif Abdelaal ${ }^{1}$, Ghada M. Galal ${ }^{1}$, Nagwa Sayed Ahmed ${ }^{2}$, Asmaa \\ Naser Mohammad ${ }^{1}$, Nahed Fathallah Fahmy ${ }^{3}$, Maha Mohamed Agamy ${ }^{1}$ \\ Department of Tropical Medicine and Gastroenterology ${ }^{1}$, Medical \\ Biochemistry ${ }^{2}$, Medical Microbiology and Immunology ${ }^{3}$, Sohag Faculty of Medicine, \\ Sohag University.
}

\begin{abstract}
Hepatocellular carcinoma (HCC) is the sixth most common cancer in the world and the fourth most common cause of cancer death.The development of HCC is a complex and multi-factorial process, in which both environmental and genetic features interfere and contribute to malignant transformation. Numerous genetic studies have reported associations between single nucleotide polymorphisms (SNPs) and the presence of HCC.The purpose of thisreview is to describethe structure ofvitamin D receptor (VDR) gene and common polymorphisms involving it, and to address the associationsbetweenVDR SNPs and cancer including HCC.
\end{abstract}

\section{Introduction}

Hepatocellular carcinoma (HCC) is the sixth most common cancer in the world and the fourth most common cause of cancer death, accounts for $75 \%$ to $85 \%$ of primary liver cancers(1). Major risk factors for $\mathrm{HCC}$ include viral infections (especially chronic HBV and HCV), cirrhosis, alcohol, and non-alcoholic fatty liver disease (NAFLD). Additional risk factors include aflatoxin, family history and genetic factors, obesity, diabetes and smoking (2).

The development of HCC is a complex and multi-factorial process, in which both environmental and genetic features interfere and contribute to malignant transformation, of great importance, gene polymorphisms of inflammatory cytokines and growth factor ligands and receptors. These genetic traits may modify the natural history of cirrhotic patients and partly explain the observed differences in the risk of HCC occurrence (3).

Vitamin $\mathrm{D}$ is involved in the metabolism of skeleton as a systemic hormone but also has important roles in the regulation of host immune responses, fibrogenesis and development of cancer through vitamin D receptor (VDR) (4). Studies have reported that vitamin $\mathrm{D}$ is implicated in inhibition of carcinogenesis by induction of

differentiation, promotion of apoptosis, and inhibition of proliferation and angiogenesis (5). The VDR gene is highly polymorphic and there aremany single nucleotide polymorphisms (SNPs) have been described and some are associated with tumor occurrence (6).

Organization of the VDR gene

The initial organization of the human VDR chromosomal gene was determined in 1988 and corresponded to the sequence of the human VDR initially reported by Baker et al. (7). VDR is encoded by a large gene (about $100 \mathrm{~kb}$ ) located on the chromosome 12q13.11 (8). The VDR gene encompasses at least two promoter regions, eight protein-coding exons (namely 2-9), and six exons that encode the 5 ' untranslated region (1a1f)(Figure 1)(9).

VDR gene polymorphisms

VDR gene has approximately 200 SNPs (10). The first techniques used to 
analyze the presence of VDR polymorphisms were done by screening with different restriction enzymes (9). Examples of this include the ApaI (rs7975232), FokI (rs2228570),EcoRV (rs4516035), BsmI (rs1544410), TaqI (rs731236), BglI (rs739837)and Tru9I (rs757343) restriction fragment length
polymorphisms(RFLPs)(Figure 1)(8). All these RFLPs are located in intron 8 between the 8 and 9 exons at the $3^{\prime}$ end of the VDR gene, except TaqI which is located at codon 352 in exon 9,FokIlocated in exon 2, and BglI located $303 \mathrm{bp}$ downstream of the stop codon (TGA) in the $3^{\prime}$ UTR(9).

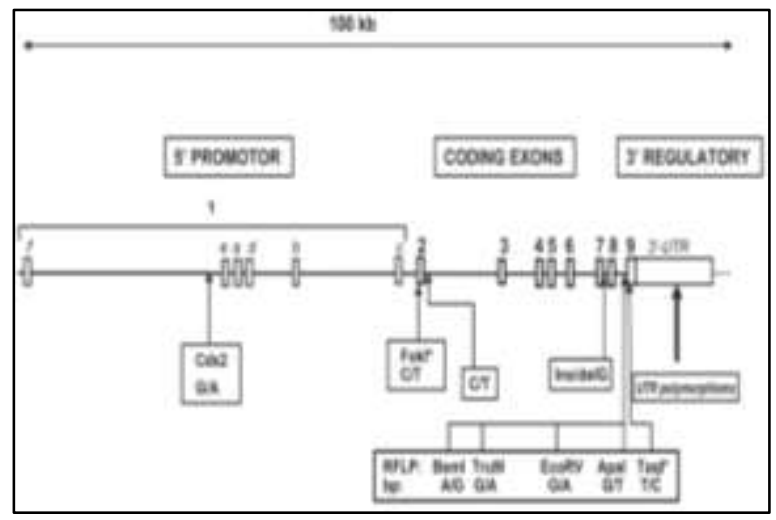

Figure (1): Organization of the human VDR gene and position of known polymorphisms. * indicates that these polymorphisms are in the coding sequence (8).

The TaqI polymorphism has been shown to be associated with lower circulating levels of active vitamin $\mathrm{D}_{3}(\mathbf{1 1})$. The ApaI, BsmI, Tru9I, EcoRV and BglI RFLPs are considered to be silent SNPs, they do not change the amino acid sequence of the encoded protein. However, they may affect gene expression through regulation of mRNA stability (12). The FokI polymorphism is the only known VDR gene polymorphism that results in the generation of an altered protein which is shorter by three amino $\operatorname{acids}(\mathbf{9})$.

Using the sequencing approach, a number of new polymorphisms have been found. For instance, a $\mathrm{C}$ to $\mathrm{T}$ change near the exon 2 and an insertion/deletion of a $\mathrm{G}$ after exon 7 was reported (13). Cdx2 (rs11568820) polymorphism was detected by the same technique, it is a $\mathrm{G}$ to $\mathrm{A}$ sequence variation in the promoter area (1e promoter) of the VDR gene, more specifically in a binding site for an intestinal-specific transcription factor which is called $\mathrm{Cdx} 2$. The A allele has been demonstrated to be more active by binding the $\mathrm{Cdx} 2$ transcription factor more strongly and by having greater transcriptional activity (14). 


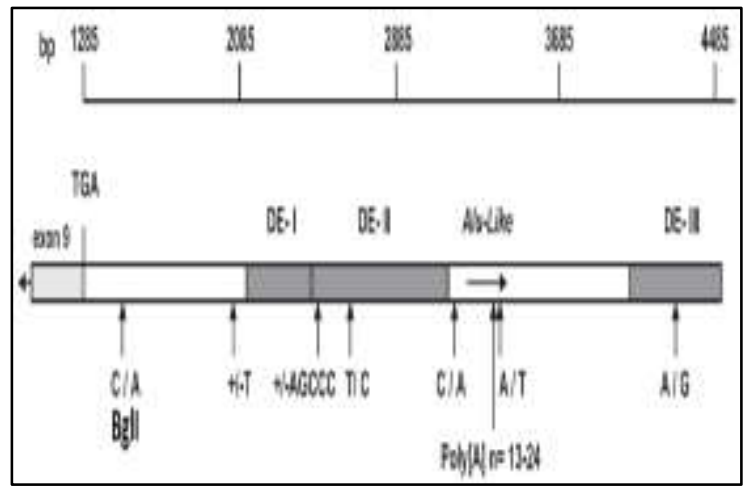

Figure (2): Structure and position of polymorphisms in the $3^{\prime}$ UTR of the VDR. The bp numbering is according to Baker et al. (1988) (7). TGA indicates the stop codon in exon 9 where the 3' UTR starts. DE, destabilising elements (8).

The $3.2 \mathrm{~kb} \mathrm{3'} \mathrm{UTR} \mathrm{of} \mathrm{the} \mathrm{VDR}$ gene is also a source of several different polymorphisms(Figure 2). However, conflicting reports over the number and position of the polymorphisms exist in the literature (15). Of particular importance, the poly (A) polymorphism, characterized by a variable number of Aresidues.Individuals can be classified as having alleles with short $(\mathrm{S}$, with $<18 \mathrm{As}$ ) or long (L, with >18 As) poly (A) stretches. The $\mathrm{S}$ allele is considered to be the more active VDR allele (9).

Several large studies reported ethnic variation in the occurrence of VDR gene polymorphisms (16). However, the functional effect of a certain polymorphism will most likely not differ between ethnic groups, most importantly because the physiological role of the vitamin $\mathrm{D}$ endocrine system is considered to be the same in all ethnic groups (9).

\section{haplotypes}

Linkage disequilibrium and

Linkage disequilibrium (LD) describes the co-occurrence of alleles of adjacent polymorphisms with each other (17). As a result, the presence of a polymorphism predicts the presence of another polymorphism that is linked to it. When there are many LDs in a certain area, there will be only a limited number of haplotypes in that area (9). Haplotypes can be defined as blocks of linked alleles of adjacent polymorphisms (18). The haplotype block size can vary between 5 to $>50$ $\mathrm{kb}$, with an average of 10-20 kb (8), and as a consequence, relatively few polymorphisms are enough to cover the variance in a certain area (9).

In general, the LD and haplotype structure of the VDR gene is important for association analyses to see whether and to what extent a certain polymorphism contributes to the risk of disease e.g. of cancer occurrence. This means that if acertain polymorphism has been found to be associated with a higher risk of cancer incidence, it must be taken into consideration that this association might also be explained by one or more other alleles that are linked to that allele within the haplotype because of LD and haplotype combination (9).

With reference to the extent of LD across the VDR gene, a strong LD has been noticed at the $3^{\prime}$ end of the gene for the BsmI, ApaI and TaqI RFLPs (19). This leads to the assumption that with reference to these three polymorphisms, there may be similar results concerning cancer risk. The most frequent haplotypes were found to be haplotype 1 (baT: 48\%) and haplotype 2 (BAt: 40\%) (20). Another LD has been observed between the BsmI RFLP and the poly 
(A) polymorphism: the two common haplotypes are bL and BS. Haplotype 1 (baT) is linked to the long poly (A) stretch (L) whereas haplotype 2 (BAt) is linked to the short poly (A) stretch (S) $(\mathbf{1 9 , 2 0})$. The TaqI RFLP is also in strong LD with the poly (A) polymorphism (21).As noticed in several studies, the FokI polymorphism is in no LD with any of the other VDR polymorphisms and, consequently, can be considered as an independent marker in the VDR gene (8).

VDR gene polymorphisms and cancer

The results of various studies suggest the crucial role of VDR polymorphism (mainly FokI, ApaI, BsmI, and TaqI) in tumorigenesis of various cancer types by affecting vitamin $\mathrm{D}$ metabolism and the cellular response to vitamin $\mathrm{D}$. It is also obvious that the association between VDR polymorphism and tumorigenesis varies with age, sex, race and ethnicity (22). VDR polymorphisms may serveas indicators for diagnosis, occurrence, and prognosis as well as survival in cancer (23).

There have been many epidemiological studies of breast, prostate, colorectal and skin cancer, however, there are limited reports on the association of VDR polymorphism with lung, thyroid, esophageal, ovarian, renal and hepatocellular carcinoma (22). Some studies reported conflicting results and others only found associations between VDR polymorphisms and cancer when other risk factors such as UVB exposure, oral vitamin $\mathrm{D}$ and calcium intake, or the plasma level of $25(\mathrm{OH}) \mathrm{D}_{3}$ were present (9). These apparent contradictions could be explained by differences in vitamin D levels, racial heterogeneity and sample size (15).

Significant associations between VDR polymorphisms and breast (FokI, BsmI, ApaI), prostate (FokI, BsmI,
TaqI), colorectal (FokI, BsmI, TaqI), skin (FokI, BsmI, TaqI), kidney (TaqI, ApaI), ovary (FokI, ApaI) and bladder cancer (FokI) have been reported, although with conflicting observations (22). Furthermore, VDR polymorphisms were found to influence the prognosis of prostate (FokI) and breast cancer (BsmI, TaqI), renal cell carcinoma (TaqI) and malignant melanoma (BsmI) (9).

VDR gene polymorphisms and liver disease

VDR polymorphisms have been investigated in the context of some chronic liver diseases, such as chronic hepatitis $\mathrm{C}(\mathrm{CHC})$, chronic hepatitis $\mathrm{B}$ (CHB), primary biliary cholangitis (PBC) and autoimmune hepatitis (AIH)(24).

In CHC infection, the bAt [CCA]-haplotype of the BsmI, ApaI, and TaqI alleles, and the CC genotype of the ApaI allele are associated with rapid fibrosis progression, cirrhosis and increased intrahepatic expression of the fibrosis marker gene matrix metallopeptidase 9(MMP-9)(25). Moreover, a strong association was observed between bAt [CCA]haplotype and treatment non-response to pegylated IFN- $\alpha /$ ribavirin therapy $(26,27)$.

In $\mathrm{CHB}$ infection, the variation in allele frequency of BsmI, ApaI, and TaqI is associated with $\mathrm{HBeAg}$ positivity and HBV flare (28). Variation in ApaI, and to a lesser extent TaqI, is associated with a higher HBV viral load and more severe fibrosis and necroinflammation(29). Variation in the TaqI VDR polymorphism is associated with both $\mathrm{CHB}$ infection and occult $\mathrm{HBV}$ infection (30).

Multiple studies have confirmed an association between VDR polymorphisms and autoimmune liver disease in both European and Asian populations. Variation in the allele 
frequency of the BsmIpolymorphism is associated with PBC (31), while variation of the FokI polymorphism is associated with AIH (32). Furthermore, carriage of the VDR BsmI-TaqI G-T/G-T diplotype is an independent predictor of acute cellular rejection post-liver transplantation (33).

\section{$\mathrm{HCC}$}

VDR gene polymorphisms and

It was found that carriage of the BsmI GG genotype and the TaqI TT genotype was strongly associated with the occurrence of HCC in patients with liver cirrhosis (34). However, there was no association between VDR BsmI GA polymorphism and HCC in patients with $\mathrm{CHB}$ infection (35) or CHC infection (36). On the contrary, it was reported that VDR polymorphisms could influence the distinct clinical phenotypes in HBV carriers, but not associated with the development of HCC (28).

In HCC complicating alcohol related cirrhosis, variation in the allele frequency of the BsmI, ApaI, and TaqI, but not FokI VDR polymorphisms was associated with HCC development when compared to cirrhotic patients without HCC, where carriage of the BAT [ATC]- and [GTT]- haplotypes was independently associated with an increased risk of HCC. Furthermore, there was a significant difference in allele frequency of these VDR polymorphisms in alcohol-related cirrhosis compared to cirrhosis complicating chronic viral hepatitis (34).

However, FokI polymorphism was significantly associated with the occurrence of $\mathrm{HCV}$ related $\mathrm{HCC}$ especially $\mathrm{T}$ allele carriers. Carriage of FokI TT genotype had a significantly higher risk for development of HCC after adjustment with age, HCV infection, BMI and HOMA-IR. This could be considered as a risk factor of
HCC and could be used as a molecular marker to predict the risk and to evaluate the disease severity of HCC in those infected with HCV (37). The same wasfound in HBV related HCC, where carriage of FokI TT genotype had a significantly higher risk for development of HCC after adjustments with age, sex, HBV infection time, AFP, smoking status, and alcohol intake. In addition, it was found that the FokI TT genotype was associated with advanced tumor stage, presence of cirrhosis, and lymph node metastasis (35). Moreover, carriage of FokI TT/CT genotypes were related to increased $\mathrm{HBV}$-related $\mathrm{HCC}$ risk as compared to FokI CC genotype (6).The FokI TT/CT genotypes and vitamin D levels had independent effect on cancer development and were not synergistic in their actions (38).

It was found that patients with HCC had a higher frequency of ApaI CC genotype and bAt [CCA]haplotype as compared to control subjects. Furthermore, it was revealed that ApaI CC genotype was an independent factor, suggesting that the ApaI C polymorphisms may be used as a molecular marker to predict the risk of HCC in the patients infected with $\mathrm{HCV}$ (24).

\section{Conclusion}

$\mathrm{HCC}$ is the sixth most common cancer in the world and the fourth most common cause of cancer death. Numerous genetic studies have reported associations between SNPs and the presence of HCC. The VDR gene is highly polymorphic and there aremany SNPs have been described and some are associated with tumor occurrence and with chronic liver disease.From the previous review we conclude that, there are limited, highly conflicting data concerning the prevalence and significance of VDR polymorphisms in $\mathrm{HCC}$ of different 
etiologies which warrant additional research.

\section{References}

1. Bray F, Ferlay J, Soerjomataram I, etal.Global cancer statistics 2018: GLOBOCAN estimates of incidence and mortality worldwide for 36 cancers in 185 countries.CA Cancer J Clin 2018; 68: 394-424.

2. Tang A, Hallouch O, Chernyak V, et al. Epidemiology of hepatocellular carcinoma: target population for surveillance and diagnosis. AbdomRadiol 2018; 43: 13-25.

3. Nahon P, Zucman-Rossi J. Single nucleotide polymorphisms and risk of hepatocellular carcinoma in cirrhosis. J Hepatol 2012; 57: 663-674.

4. Raimondi S, Johansson H, Maisonneuve $\mathbf{P}$, et al. Review and meta-analysis on vitamin $\mathrm{D}$ receptor polymorphisms and cancer risk. Carcinogenesis 2009; 30: 1170-1180.

5. BikleD.Nonclassic actions of vitamin D.J ClinEndocrinolMetab 2009; 94: 26-34.

6. Peng $Q$, Yang $S$, Lao $X$, et al. Association of single nucleotide polymorphisms in VDR and DBP genes with HBV related hepatocellular carcinoma risk in a Chinese population. PloS one 2014; 9: e116026.

7. Baker AR, McDonnell DP, Hughes $\mathbf{M}$, et al. Cloning and expression of full-length cDNA encoding human vitamin D receptor. ProcNatlAcadSci USA 1988; 85: 3294-3298.

8. Uitterlinden AG, Fang Y, Van Meurs $\mathbf{J B}$, et al. Genetics and biology of vitamin D receptor polymorphisms. Gene 2004; 338: 143-156.

9. Köstner K, Denzer N, Müller CS, et al. The relevance of vitamin $\mathrm{D}$ receptor (VDR) gene polymorphisms for cancer: a review of the literature. Anticancer Res 2009; 29: 3511-3536.

10.Fuhrman BJ, Freedman DM, Bhatti P, et al. Sunlight, polymorphisms of vitamin D-related genes and risk of breast cancer. Anticancer Res 2013; 33: 543-551.

11.Ma J, Stampfer MJ, Gann PH, et al. Vitamin D receptor polymorphisms, circulating vit $\mathrm{D}$ metabolites, and risk of prostate cancer in United states physicians. Cancer Epidemiol Biomarkers Prev 1998; 7: 385-390.

12.Jurutka PW, Whitfield GK, Hsieh JC, et al. Molecular nature of vitamin $\mathrm{D}$ receptor and its role in regulation of gene expression. Rev EndocrinMetabDisord 2001; 2: $203-$ 216.

13.Brown SB, Brierley TT, Palanisamy $\mathbf{N}$, et al. Vitamin $\mathrm{D}$ receptor as a candidate tumor-suppressor gene in severe hyperparathyroidism of uremia. J ClinEndocrinolMetab 2000; 85: 868872.

14.Arai H, Miyamoto K, Yoshida M, et al. The polymorphism in the caudalrelated homeodomain protein $\mathrm{Cdx}-2$ binding element in the human vitamin $\mathrm{D}$ receptor gene. J Bone Miner Res 2001; 16: 1256-1264.

15.Valdivielso JM, Fernandez E. Vitamin D receptor polymorphisms and diseases. ClinChimActa 2006; 371: 112.

16.Zmuda JM, Cauley JA, Ferell RE. Molecular epidemiology of vitamin D receptor gene variants. Epidemiol Rev 2000; 22: 203-217.

17.Wall JD, Pritchard JK. Haplotype blocks and linkage disequilibrium in the human genome. Nat Rev Genet 2003; 4: 587-597.

18.Gabriel SB, Schaffner SF, Nguyen H, et al. The structure of haplotype blocks in the human genome. Science 2002; 296: 2225-2229.

19.Durrin LK, Haile RW, Ingles SA, etal.Vitamin D receptor 3'untranslated region polymorphisms: lack of effect on mRNA stability. BiochimBiophysActaMol Basis Dis 1999; 1453: 311-320.

20.Uitterlinden AG, Pols HA, Burger $H$, et al. A large-scale population-based study of the association of vitamin D receptor gene polymorphisms with bone mineral density. J Bone Miner Res 1996; 11: 1241-1248.

21.Blazer DG $3^{\text {rd }}$, Umbach DM, Bostick RM, et al. Vitamin D receptor polymorphisms and prostate cancer. Mol Carcinogen 2000; 27: 18-23.

22.Rai V, Abdo J, Agrawal S, et al. Vitamin D receptor polymorphism and 
cancer: an update. Anticancer Res 2017; 37: 3991-4003.

23.Choi JY, Yi JW, Lee JH, et al. VDR mRNA overexpression is associated with worse prognostic factors in papillary thyroid carcinoma. Endocr Connect 2017; 6: 172-178.

24.Hung CH, Chiu YC, Hu TH, et al. Significance of vitamin D receptor gene polymorphisms for risk of hepatocellular carcinoma in chronic hepatitis C. TranslOncol 2014; 7: 503507.

25.Baur K, Mertens JC, Schmitt J, et al. Combined effect of $25-\mathrm{OH}$ vitamin D plasma levels and genetic vitamin $\mathrm{D}$ receptor (NR 1I1) variants on fibrosis progression rate in $\mathrm{HCV}$ patients. Liver Int 2012; 32: 635-643.

26.Baur K, Mertens JC, Schmitt J, et al. The vitamin $\mathrm{D}$ receptor gene bAt (CCA) haplotype impairs the response to pegylated-interferon/ribavirin-based therapy in chronic hepatitis $\mathrm{C}$ patients. AntivirTher 2012; 17: 541-547.

27.García-Martín E, Agúndez JA, Maestro ML, et al. Influence of vitamin D-related gene polymorphisms (CYP27B and VDR) on the response to interferon/ribavirin therapy in chronic hepatitis C. PloS one 2013; 8: e74764.

28.Huang YW, Liao YT, Chen W, et al. Vitamin D receptor gene polymorphisms and distinct clinical phenotypes of hepatitis B carriers in Taiwan. Genes Immun 2010; 11: 8793.

29.Suneetha PV, Sarin SK, Goyal A, et al. Association between vitamin D receptor, CCR5, TNF-a and TNF-b gene polymorphisms and HBV infection and severity of liver disease. $\mathrm{J}$ Hepatol 2006; 44: 856-863.

30.Arababadi MK, Pourfathollah AA, Jafarzadeh A, et al. Association of exon 9 but not intron 8 VDR polymorphisms with occult HBV infection in south-eastern Iranian patients. J GastroenterolHepatol 2010; 25: 90-93.

31.Tanaka A, Nezu S, Uegaki S, et al. Vitamin D receptor polymorphisms are associated with increased susceptibility to primary biliary cirrhosis in Japanese and Italian populations. J Hepatol 2009; 50: 1202-1209.

32.Fan L, Tu X, Zhu Y, et al. Genetic association of vitamin $\mathrm{D}$ receptor polymorphisms with autoimmune hepatitis and primary biliary cirrhosis in the Chinese. J GastroenterolHepatol 2005; 20: 249-255.

33.Falleti E, Bitetto D, Fabris C, et al. Association between vitamin D receptor genetic polymorphisms and acute cellular rejection in livertransplanted patients. TransplInt 2012; 25: 314-322.

34.Falleti E, Bitetto D, Fabris C, et al. Vitamin D receptor gene polymorphisms and hepatocellular carcinoma in alcoholic cirrhosis. World J Gastroenterol 2010; 16: 3016-3024.

35. Yao $X$, Zeng $H$, Zhang $G$, et al. The associated ion between the VDR gene polymorphisms and susceptibility to hepatocellular carcinoma and the clinicopathological features in subjects infected with HBV. Biomed Res Int 2013; 2013: 953974.

36. Youssef EM, Mohamed FS, Edreis AE, et al. Evaluation of OPN level and VDR gene polymorphism in patients with hepatocellular carcinoma. Res Cancer Tumor 2016; 5: 10-16.

37.Nada HA, Elsamanoudy AZ, Elalfy HA, et al. Study of vitamin D receptorFOK-I gene polymorphism in chronic hepatitis $\mathrm{C}$ induced hepatocellular carcinoma patients: a case control study. Int. J Innov Res SciEngTechnol 2016; 4: 4645-4655.

38. Mohapatra S, Saxena A, Gandhi G, et al. Vitamin $\mathrm{D}$ and VDR gene polymorphism (FokI) in epithelial ovarian cancer in Indian population. Journal of ovarian research 2013; 6: 37. 